\title{
Interval training based on ventilatory anaerobic threshold increases cardiac vagal modulation and decreases high-sensitivity c-reative protein: randomized clinical trial in coronary artery disease
}

\author{
Nayara Y. Tamburus ${ }^{1}$, Roberta F. L. Paula ${ }^{2}$, Vandeni C. Kunz ${ }^{3}$,
} Marcelo C. César ${ }^{4}$, Marlene A. Moreno ${ }^{2}$, Ester da Silva ${ }^{1}$

\begin{abstract}
Background: Autonomic dysfunction and inflammatory activity are involved in the development and progression of coronary artery disease (CAD), and exercise training has been shown to confer a cardiovascular benefit. Objective: To evaluate the effects that interval training (IT) based on ventilatory anaerobic threshold (VAT) has on heart rate variability (HRV) and high-sensitivity C-reactive protein (hs-CRP) levels, as well as the relationship between both levels, in patients with CAD and/or cardiovascular risk factors (RF). Method: Forty-two men (aged 57.88 \pm 6.20 years) were divided into two training groups, CAD-T $(n=12)$ and RF-T $(n=10)$, and two control groups, CAD-C $(n=10)$ and $\mathrm{RF}-\mathrm{C}(\mathrm{n}=10)$. Heart rate and RR intervals in the supine position, cardiopulmonary exercise tests, and hs-CRP levels were measured before and after IT. HRV was analyzed by spectral and symbolic analysis. The CAD-T and RF-T underwent a 16-week IT program of three weekly sessions at training intensities based on the VAT. Results: In the RF-T, cardiac sympathetic modulation index and hs-CRP decreased $(\mathrm{p}<0.02)$, while cardiac parasympathetic modulation index increased $(\mathrm{p}<0.02)$. In the CAD-T, cardiac parasympathetic modulation index increased, while hs-CRP, systolic, and diastolic blood pressures decreased $(\mathrm{p}<0.02)$. Both control groups showed increase in hs-CRP parameters $(\mathrm{p}<0.02)$. There was a strong and significant association between parasympathetic and sympathetic modulations with hs-CRP. Conclusion: The IT program based on the VAT promoted a decrease in hs-CRP associated with improvement in cardiac autonomic modulation.
\end{abstract} Keywords: physical therapy; coronary disease; exercise; C-reactive protein; heart rate variability.

ClinicalTrials.gov Identifier: NCT02313831

\section{BULLET POINTS}

- Autonomic dysfunction and inflammation are present in coronary artery disease.

- Interval training (IT) is a new protocol applied to cardiac rehabilitation.

- Ventilatory anaerobic threshold is a good parameter to prescribe exercise intensity.

- Parasympathetic modulation can be related to a reduction in inflammation after IT.

- These findings reinforce the anti-inflammatory effects of exercise.

\section{HOW TO CITE THIS ARTICLE}

Tamburus NY, Paula RFL, Kunz VC, César MC, Moreno MA, Silva E. Interval training based on ventilatory anaerobic threshold increases cardiac vagal modulation and decreases high-sensitivity c-reative protein: randomized clinical trial in coronary artery disease. Braz J Phys Ther. 2015 Nov-Dec; 19(6):441-450. http://dx.doi.org/10.1590/bjpt-rbf.2014.0124

\section{Introduction}

Autonomic dysfunction and increased circulating levels of inflammatory biomarkers are interrelated risk factors implicated in the etiology of coronary artery disease $(\mathrm{CAD})^{1}$ and other cardiovascular diseases ${ }^{2}$. Recent studies have explored the link between the autonomic nervous system (ANS) and markers of inflammation ${ }^{1,3}$. These previous studies have proposed a relationship between increased high-sensitivity C-reactive protein (hs-CRP) levels and decreased vagal modulation in patients with $\mathrm{CAD}$, which is also associated with an increased risk of cardiovascular events and progression of $\mathrm{CAD}^{1,3}$. On the other hand, it has been reported that the parasympathetic nervous system may inhibit inflammation by discharging

\footnotetext{
${ }^{1}$ Núcleo de Pesquisa em Exercício Físico, Departamento de Fisioterapia, Universidade Federal de São Carlos (UFSCar), São Carlos, SP, Brazil

${ }^{2}$ Faculdade de Ciências da Saúde, Universidade Metodista de Piracicaba (UNIMEP), Piracicaba, SP, Brazil

${ }^{3}$ Centro Universitário Adventista (UNASP), Engenheiro Coelho, SP, Brazil

${ }^{4}$ Laboratório de Performance Humana, Faculdade de Ciências da Saúde, UNIMEP, Piracicaba, SP, Brazil

Received: Aug. 02, 2014 Revised: Jan. 21, 2015 Accepted: June 07, 2015
} 
acetylcholine and suppressing the synthesis and release of pro-inflammatory cytokines ${ }^{4}$.

Aerobic exercise training promotes positive autonomic adaptations ${ }^{5}$, which may be evidenced by an increase in cardiac parasympathetic modulation. Among several types of exercise protocol, interval training (IT) has gained considerable attention as a suitable exercise program for patients with $\mathrm{CAD}^{6,7}$. Several studies suggest that high-intensity IT promotes more evident cardiovascular adaptions than low and moderate intensity of exercise in patients with $\mathrm{CAD}^{8,9}$. Regarding autonomic adaptation, Currie et al. ${ }^{7}$ reported that neither moderate-intensity endurance exercise nor novel low-volume high-intensity interval exercise protocol programs promoted improvements in cardiac autonomic function in patients with CAD. In contrast, Munk et al. ${ }^{10}$ showed that high-intensity IT leads to consistent favorable effects on heart rate variability (HRV).

Despite these findings, there is a scarcity of clinical data on the effects of IT at intensities close to the ventilatory anaerobic threshold (VAT) on autonomic modulation of heart rate (HR). Moreover, it is still unclear whether the increase in parasympathetic modulation is related to a reduction in inflammation after the IT program.

Therefore, the purpose of this study was to evaluate the effects that IT based on the VAT might have on HRV and hs-CRP levels, as well as the relationship between both parameters, in patients with CAD and/or cardiovascular risk factors (RF). We hypothesized that the proposed IT program would improve HRV indices, as evidenced by increased parasympathetic modulation and decreased sympathetic modulation, in association with a decrease circulating levels of hs-CRP.

\section{Method}

\section{Subjects}

The study was designed as a randomized clinical trial (ClinicalTrials.gov Identifier: NCT02313831). A sample of 139 male subjects was interviewed and considered eligible for the study based on the results of coronary angiography performed at Centro de Hemodinâmica do Hospital Santa Isabel, Piracicaba, SP, Brazil. All subjects were screened and classified as either CAD or RF according to the following criteria: $\mathrm{CAD}$ - subjects with angiographic evidence of $\geq 50 \%$ of stenosis in one or more major coronary vessels or previous coronary artery intervention, such as percutaneous coronary intervention (PCI) and coronary artery bypass graft (CABG); RF - subjects without stenosis in coronary vessels (angiographically documented) and without a history of previous myocardial infarction (MI), PCI or CABG. All subjects presented three or more cardiovascular RF, such as obesity (body mass index $>30 \mathrm{~kg} / \mathrm{m}^{2}$ ), hypertension, diabetes mellitus (type 2 - nonusers of insulin), dyslipidemia, smoking, and sedentary lifestyle according to the International Physical Activity Questionnaire (IPAQ) version 6. The exclusion criteria consisted of $\mathrm{MI}<6$ months, $\mathrm{PCI}$ and $\mathrm{CABG}<3$ months, frequent arrhythmias, pulmonary disease, unstable angina, osteomuscular disorders, insulin-dependent diabetes mellitus, neoplasia, renal failure, and sequelae associated with stroke.

In this study, 42 men were selected ( 22 with CAD and 20 with only cardiovascular RF) according to the inclusion criteria. The flowchart of the progress of the study is presented in Figure 1, and subject characteristics are described in Table 1. All subjects performed a resting 12-lead electrocardiogram and a maximal or symptom-limited exercise test using the Bruce treadmill protocol under the supervision of a cardiologist with the objective of pre-exercise screening and risk stratification for physical activity. Following the exercise testing, a random number table was used to allocate the $\mathrm{CAD}$ subjects to trained group (CAD-T, $\mathrm{n}=12$ ) or control group (CAD-C, $\mathrm{n}=10$ ) and the RF subjects to trained group (RF-T, n=10) or control group (RF-C, $\mathrm{n}=10$ ).

All subjects signed an informed consent form prior to participating in the study, which was approved by the Ethics Committee of Universidade Metodista de Piracicaba (UNIMEP), Piracicaba, SP, Brazil (Protocol 34/12).

\section{Experimental procedures}

All experimental procedures were performed in the morning. The room temperature and relative air humidity of the testing laboratory were kept at $23^{\circ} \mathrm{C}$ and between $40 \%$ and $60 \%$, respectively. Before the experimental procedures, all subjects were familiarized with the equipment and experimental protocol to reduce anxiety. They were then instructed to abstain from stimulants (coffee, tea, soft drinks) and alcoholic beverages, avoid exhausting physical activity in the $24 \mathrm{~h}$ prior to the test, and have a light meal at least $2 \mathrm{~h}$ before the experiment. 


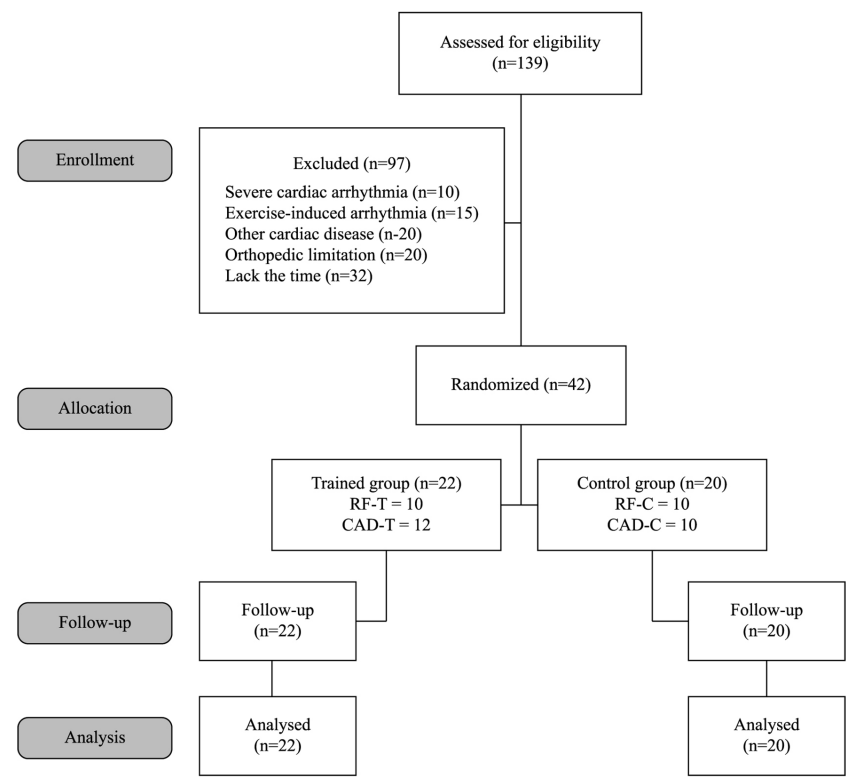

Figure 1. Flowchart showing patient participation in the study. CAD-T= trained group with patients with coronary artery disease; $\mathrm{CAD}-\mathrm{C}=$ control group with patients with coronary artery disease; $\mathrm{RF}-\mathrm{T}=$ trained group with patients with cardiovascular risk factors; $\mathrm{RF}-\mathrm{C}=$ control group with patients with cardiovascular risk factors.

\section{Blood plasma parameters}

After an overnight 12-h fast, venous blood samples were drawn to analyze the following parameters: fasting glucose, total cholesterol (using the autoanalyzer method), high-density lipoprotein (HDL) and low-density lipoprotein (LDL) cholesterol (using enzymatic colorimetry), triglycerides (using automated enzymatic methods), and hs-CRP(with the nephelometric method).

\section{Measurement and analysis of HRV}

Each subject's HR and RR intervals were measured for 15 minutes with a digital telemetry system consisting of a transmitter placed on the chest and a HR monitor (Polar ${ }^{\circledR}$ S810i; Polar Electro Oy, Kempele, Finland) previously validated by Gamelin et al. ${ }^{11}$. The measurements were obtained with the subjects in the supine position while breathing spontaneously (i.e. $\approx 14$ breaths per minute).

After transferring the data to the computer, 300 consecutive beats were selected after the length of greatest stability was chosen from the central region of the time series. The initial and final RR intervals were discarded. The HRV was evaluated based on spectral $^{12}$ and symbolic analyses ${ }^{13}$. The same sequence was used for both the spectral and the symbolic analysis. Detailed procedures for HRV analysis were as previously described ${ }^{12,13}$.

\section{Cardiopulmonary exercise test (CPET)}

Each subject underwent submaximal CPET on a cycle ergometer with an electromagnetic brake (Corival V2, Lode B.V., Groningen, The Netherlands) to determine the VAT before IT. Workload increments were determined for each subject according to the formula proposed by Wasserman et al. ${ }^{14}$ (Workload increase $(\mathrm{W})=[($ height - age $) \times 20]-[150+(6 \times$ body mass) $] / 100$ ). CPET was performed with $1 \mathrm{~min}$ baseline; 4 min unloaded cycling, followed by the workload increments. The test was interrupted when the patients had symptom- and/or sign-limited HR (pallor, unusual sweating patterns, nausea, vomiting, physical exultation, dimmed or blurred vision, dyspnea, and abnormal response of SBP and HR in progressive workloads) or attained submaximal HR $(85 \% \text { of maximum HR })^{15}$. Ventilatory and metabolic measurements were obtained on a breath-by-breath basis using a metabolic analyzer (CPX-D, Medical Graphics, St. Paul, MN, USA). HR was monitored throughout the test using a 12-lead electrocardiogram (Welch Allyn CardioPerfect Workstation, Skaneateles Falls, NY, USA).

The VAT was determined from a loss of parallelism between $\mathrm{VO}_{2}$ (oxygen consumption) and $\mathrm{VCO}_{2}$ (carbon dioxide output) by three properly trained observers, as previously described by Zamunér et al. ${ }^{16}$ and Higa et al. ${ }^{17}$. 
Table 1. Baseline clinical characteristics of the trained and control groups.

\begin{tabular}{|c|c|c|c|c|}
\hline \multirow{2}{*}{ Variables } & \multicolumn{2}{|c|}{ Trained } & \multicolumn{2}{|c|}{ Control } \\
\hline & RF (n=10) & CAD (n=12) & RF (n=10) & CAD (n=10) \\
\hline Age (years) & $58.9 \pm 4.0$ & $56.2 \pm 7.4$ & $56.3 \pm 6.2$ & $60.4 \pm 6.1$ \\
\hline \multicolumn{5}{|c|}{ Clinical characteristics - number of patients $(\%)$} \\
\hline Myocardial infarction & $0(0.0 \%)$ & $4(33.3 \%)$ & $0(0.0 \%)$ & $2(20.0 \%)$ \\
\hline Coronary artery bypass surgery & $0(0.0 \%)$ & $4(33.3 \%)$ & $0(0.0 \%)$ & $4(40.0 \%)$ \\
\hline Percutaneous coronary intervention & $0(0.0 \%)$ & $8(66.6 \%)$ & $0(0.0 \%)$ & $6(60.0 \%)$ \\
\hline \multicolumn{5}{|l|}{ Medication - number of patients (\%) } \\
\hline Beta blockers & $4(40.0 \%)$ & $7(58.3 \%)$ & $4(40.0 \%)$ & $5(50.0 \%)$ \\
\hline ACE inhibitors & $3(30.0 \%)$ & $7(58.3 \%)$ & $7(70.0 \%)$ & $4(40.0 \%)$ \\
\hline Hypolipidemic agents & $5(50.0 \%)$ & $10(83.3 \%)$ & $2(20.0 \%)$ & $8(80.0 \%)$ \\
\hline Diuretics & $1(20.0 \%)$ & $3(25.0 \%)$ & $2(20.0 \%)$ & $2(20.0 \%)$ \\
\hline Antiplatelet agents & $4(40.0 \%)$ & $10(83.3 \%)$ & $6(60.0 \%)$ & $9(90.0 \%)$ \\
\hline Hypoglycemic agents & $0(0.0 \%)$ & $1(8.3 \%)$ & $2(20.0 \%)$ & $2(20.0 \%)$ \\
\hline \multicolumn{5}{|l|}{ Risk factor - number of patients $(\%)$} \\
\hline Smoking & $1(10.0 \%)$ & $3(25.0 \%)$ & $3(30.0 \%)$ & $1(10.0 \%)$ \\
\hline Sedentary lifestyle (IPAQ) & $10(100.0 \%)$ & $12(100.0 \%)$ & $10(100.0 \%)$ & $10(100.0 \%)$ \\
\hline Dyslipidemia & $7(70.0 \%)$ & $10(83.3 \%)$ & $3(30.0 \%)$ & $9(90.0 \%)$ \\
\hline Hypertension $(140 / 90 \mathrm{mHg})$ & $5(50.0 \%)$ & $8(66.6 \%)$ & $7(70.0 \%)$ & $7(70.0 \%)$ \\
\hline Obesity $\left(\mathrm{BMI} \geq 30 \mathrm{~kg} / \mathrm{m}^{2}\right)$ & $1(10.0 \%)$ & $5(41.6 \%)$ & $3(30.0 \%)$ & $3(30.0 \%)$ \\
\hline Diabetes mellitus & $0(0.0 \%)$ & $1(8.3 \%)$ & $2(20.0 \%)$ & $2(20.0 \%)$ \\
\hline \multicolumn{5}{|l|}{ Metabolic variables } \\
\hline Triglycerides (mg/dL) & $119.9 \pm 59.1$ & $154.2 \pm 70.0$ & $138.8 \pm 44.4$ & $153.1 \pm 74.0$ \\
\hline Total cholesterol (mg/dL) & $177.7 \pm 46.7$ & $172.2 \pm 50.1$ & $164.8 \pm 24.0$ & $171.6 \pm 22.1$ \\
\hline Fasting glucose $(\mathrm{mg} / \mathrm{dL})$ & $93.2 \pm 7.5$ & $98.2 \pm 10.9$ & $90.0 \pm 10.0$ & $97.2 \pm 12.1$ \\
\hline HDL cholesterol (mg/dL) & $48.1 \pm 20.1$ & $40.7 \pm 10.5$ & $39.9 \pm 11.6$ & $39.1 \pm 9.8$ \\
\hline LDL cholesterol (mg/dL) & $97.2 \pm 29.5$ & $105.6 \pm 34.3$ & $100.7 \pm 17.9$ & $98.7 \pm 26.4$ \\
\hline \multicolumn{5}{|l|}{ Ventilatory anaerobic threshold } \\
\hline $\mathrm{VO}_{2}\left(\mathrm{~mL} \cdot \mathrm{kg}^{-1} \cdot \mathrm{min}^{-1}\right)$ & $14.5 \pm 2.4$ & $13.50 \pm 2.14$ & $14.38 \pm 2.06$ & $13.15 \pm 3.33$ \\
\hline $\mathrm{VO}_{2}\left(\mathrm{~L} \cdot \mathrm{min}^{-1}\right)$ & $1.15 \pm 0.24$ & $1.12 \pm 0.25$ & $1.14 \pm 0.28$ & $1.08 \pm 0.20$ \\
\hline HR (bpm) & $105.6 \pm 15.1$ & $106.9 \pm 12.7$ & $115.7 \pm 22.3$ & $103.4 \pm 24.4$ \\
\hline Workload (W) & $82.6 \pm 28.0$ & $80.2 \pm 6.8$ & $84.3 \pm 24.3$ & $81.7 \pm 17.3$ \\
\hline
\end{tabular}

Values are represented as mean $\pm \mathrm{SD}$, except where indicated. $\mathrm{CAD}=$ coronary artery disease; $\mathrm{RF}=$ risk factor; $\mathrm{ACE}=$ angiotensin converting enzyme; IPAQ = International Physical Activity Questionnaire; HDL = high-density lipoprotein; LDL = low-density lipoprotein; $\mathrm{VO}_{2}=$ oxygen consumption; $\mathrm{HR}=$ heart rate; $\mathrm{bpm}=$ beats per minute; $\mathrm{W}=$ watts .

\section{Interval training program}

The IT program was individualized and administered three times per week (on alternate days) for a 16-week period. Each exercise session lasted approximately $60 \mathrm{~min}$ and was divided into three parts as follows: 1) Warm-up (10 min) including stretching, calisthenics, and low-intensity exercises (walking); 2) Exercise training protocol (Figure 2) performed on a stationary cycle ergometer (30-40 min $)^{18,19}$ and was divided into 6 steps: Step 1-5-min at moderate intensity with the aim of reaching $80 \%$ of the workload attained at VAT;
Step 2 and $4-5$-min and progressing up to 10-min at moderate-high intensity with the aim of reaching $100 \%$ of the workload attained at VAT; Step 3 and $5-5$-min at moderate to high intensity with the aim of reaching $110 \%$ of the workload attained at VAT; Step 6-5-min at moderate intensity with the aim of reaching $70 \%$ of workload attained at VAT. The moderate and moderate-high intensities were comprised, thus eliciting the aerobic and the anaerobic metabolism. 3) Cool-down (10 min) consisted of stretching and respiratory exercises to allow the $\mathrm{BP}$ and $\mathrm{HR}$ values 
to return to their near-basal values. Polar HR monitors (Polar ${ }^{\circledR}$ S810i; Polar Electro Oy, Kempele, Finland) were worn during each exercise session to ensure that patients exercised at the targeted intensity.

The intensity of the physical training was adjusted on a monthly basis, following the methodology proposed by Sirol et al. ${ }^{18}$ and Pithon et al. ${ }^{19}$, by determining the anaerobic threshold from the HR response. HR response was analyzed during discontinuous exercise testing on cycle ergometer in each workload applied. HR data behavior was analyzed based in mathematical and statistical models, whereby evaluated the loss of stability of the HR response (decreasing, stable, or increasing response as a function of time). A positive slope and statistically significant was considered as workload at VAT level, which has been attributed to the beginning of the predominance of sympathetic activation. Thus, the physical training intensity levels were adjusted based on the HR data at the power output level corresponding to the positive slope of HR.

\section{Statistical analysis}

Based on the pilot study ( $\mathrm{n}=6$ ), the sample size was calculated using GPower software (version 3.1) considering a $5 \%$ chance of type I error, a 2 -sided test, and a power of $80 \%$ power, according to Lara Fernandes et al. ${ }^{20}$. The outcome variable considered for the sample size calculation was hs-CRP, based on analysis of variance (repeated measures; within-between interaction), which provided an effect size (ES) of 0.77. A final sample of 10 patients in each group was suggested. According to the frequency distribution analysis (Shapiro-Wilk test), the data did not show a normal distribution. Baseline clinical characteristics are presented as means \pm standard deviation. Hemodynamic variables at rest, HRV indices, and hs-CRP levels are presented as medians (interquartile range). The Mann-Whitney test was performed for intergroup comparison, and the Wilcoxon test was used for intragroup comparison. To adjust for multiple comparisons, the Bonferroni correction was used at a significance level of $p<0.02$. The ES for each mean difference was calculated using Cohen's $\mathrm{d}^{21}$. The thresholds used for interpretation were as follows: values $>0.2$ to $0.5=$ small $\mathrm{ES},>0.5$ to $0.8=$ medium $\mathrm{ES}$, and $>0.8=$ large ES.

Analysis of covariance (ANCOVA) and linear regression were used to assess the relationship between HRV indices and hs-CRP (dependent variables), as well as covariates (independent variables) such as clinical variables, use of medication, and risk factors (Table 1). The correlation between HRV indices and hs-CRP was analyzed using partial correlation adjusted for the following covariates: clinical variables, use of medication, and risk factors, based on their significance in the covariance test (ANCOVA). The correlation coefficient was calculated $(\mathrm{r}=0.40$ to 0.50 , weak correlation; $r=0.6$ to 0.7 , moderate correlation; $r=>0.8$, strong correlation). Significance was established at the level of $\mathrm{p}<0.05(\alpha=5 \%)$.

All statistical analyses were performed using the software packages STATISTICA for Windows 7.0 and $\mathrm{R}$ version 2.9.0 for Windows.

\section{Results}

There were no changes in anthropometrics characteristics at baseline and after follow-up in trained and control groups. At baseline, the resting systolic $\mathrm{BP}$, diastolic BP and HR did not differ significantly among trained and control groups $(p>0.02)$. After IT, a significant decrease in resting systolic and diastolic $\mathrm{BP}$ values was noted in the CAD-T group $(p<0.02)$. Moreover, systolic $(p<0.02)$ and diastolic BP $(p<0.02)$ values were significantly lower in the RF-T group compared to the RF-C group. The ES was considered large for systolic and diastolic BP. Neither of the control groups showed any detectable changes after 16 weeks ( $>0.02)$ (Table 2).

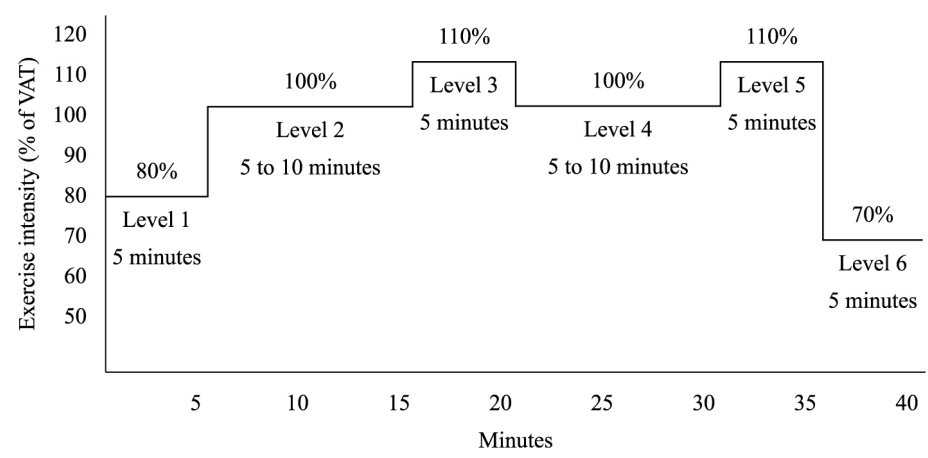

Figure 2. Visual presentation of intensity levels and duration performed during of interval training. VAT= ventilatory anaerobic threshold. 


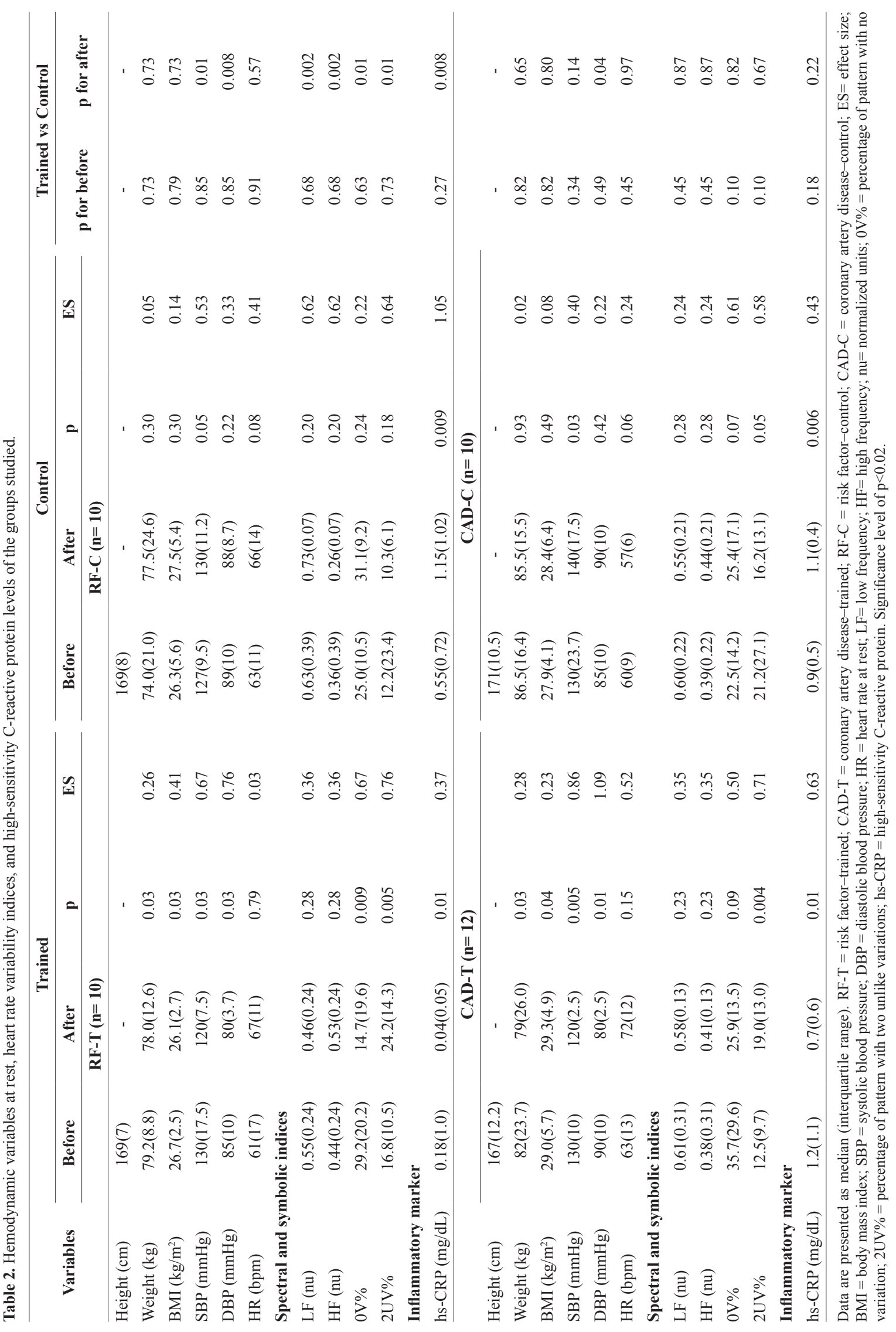


At baseline, there were no significant differences in HRV indices ( $0 \mathrm{~V} \%$ and $2 \mathrm{UV} \%$; LFnu and HFnu) between trained and control groups. In the RF-T group, only $0 \mathrm{~V} \%$ (sympathetic modulation) values decreased after IT $(\mathrm{p}<0.02)$, while in the CAD-T group, LFnu and $0 \mathrm{~V} \%$ did not differ significantly at baseline ( $>0.02$ ). For both trained groups, $0 \mathrm{~V} \%$ presented medium ES. Moreover, only the RF-T group presented higher LFnu and $0 \mathrm{UV} \%$ values than the RF-C group ( $\mathrm{p}=0.01)$.

Regarding parasympathetic modulation, only $2 \mathrm{UV} \%$ values increased significantly in the RF-T and CAD-T groups $(\mathrm{p}<0.02)$ after IT. For both trained group, $2 \mathrm{UV} \%$ presented medium ES. Moreover, the RF-T group presented higher HFnu and $2 \mathrm{UV} \%$ values than the RF-C group $(\mathrm{p}<0.02)$, while the HFnu and $2 \mathrm{UV} \%$ values of the CAD-T and CAD-C groups did not differ significantly $(\mathrm{p}>0.02)$. None of the HRV indices in the control groups showed any significant changes after 16 weeks.

There were no significant differences among groups in hs-CRP level at baseline. After IT, the hs-CRP level in the RF-T and CAD-T groups diminished significantly $(\mathrm{p}<0.02)$, while in both control groups increased significantly $(\mathrm{p}<0.02)$. For the RF-T group, hs-CRP presented small ES, while in the CAD-T group, the ES was medium. Furthermore, the levels of hs-CRP ( $p=0.008)$ in the RF-T group were lower than those observed in the RF-C group.

\section{Analysis of covariance (ANCOVA) and linear regression}

The linear regression examined the association of the use of medication and risk factors with the hs-CRP levels and only symbolic indices. Use of betablockers accounted for $51 \%$ of the variance in $0 \mathrm{~V} \%$ in the RF-T group $(\mathrm{p}<0.05)$. In the CAD-T group, however, the use of beta-blockers and angiotensinconverting enzyme (ACE) inhibitors, dyslipidemia, and hypertension accounted for $65 \%$ of the variance in $0 \mathrm{~V} \%(\mathrm{p}<0.05)$. Furthermore, the use of beta-blockers and ACE inhibitors as well as dyslipidemia accounted for $62 \%$ of the variance in $2 \mathrm{UV} \%$ in the CAD-T group $(p<0.05)$. The covariates that accounted for $50 \%$ of the variance in hs-CRP levels included PCI $>3$ months, use of ACE inhibitors, hypolipidemic agents, and dyslipidemia in the CAD-T group $(\mathrm{p}<0.05)$.

In the RF-C group, the use of beta-blockers, hypertension and obesity explained $69 \%$ of the variance in $2 \mathrm{UV} \%(\mathrm{p}<0.05)$. In the CAD-C group, dyslipidemia, hypertension, and obesity explained $64 \%$ of the variance in $0 \mathrm{~V} \%(\mathrm{p}<0.05)$. All of the models satisfied the hypotheses of homoscedasticity and normality of residuals (Table 3 ).

Table 3. Analysis of covariance (ANCOVA) and linear regression analysis of HRV indices and hs-CRP and the covariates for the trained and control groups.

\begin{tabular}{|c|c|c|c|c|c|c|}
\hline Groups & $\begin{array}{c}\text { Dependent } \\
\text { variables }\end{array}$ & Covariates & $\mathbf{P}$ & Intercept & Estimate & $\mathbf{r}^{2}$ \\
\hline FT-T & $0 \mathrm{~V} \%$ & Beta blocker & 0.02 & 28.96 & -14.69 & 0.51 \\
\hline \multirow{3}{*}{ CAD-T } & $0 \mathrm{~V} \%$ & $\begin{array}{l}\text { Beta blocker } \\
\text { ACE inhibitor } \\
\text { Dyslipidemia } \\
\text { Hypertension }\end{array}$ & $\begin{array}{l}0.05 \\
0.03 \\
0.005 \\
0.01\end{array}$ & 38.03 & \begin{tabular}{r|}
-17.43 \\
-12.78 \\
10.14 \\
18.41 \\
\end{tabular} & 0.65 \\
\hline & $2 \mathrm{UV} \%$ & $\begin{array}{l}\text { Beta blocker } \\
\text { ACE inhibitor } \\
\text { Dyslipidemia }\end{array}$ & $\begin{array}{l}0.02 \\
0.05 \\
0.007\end{array}$ & 9.48 & $\begin{array}{l}10.74 \\
11.22 \\
-5.65\end{array}$ & 0.62 \\
\hline & hs-CRP & $\begin{array}{l}\text { ACE inhibitor } \\
\text { Hypolipidemic } \\
\text { PCI }\end{array}$ & $\begin{array}{l}0.04 \\
0.03 \\
0.01\end{array}$ & 1.17 & $\begin{array}{l}-9.25 \\
-0.18 \\
-0.20\end{array}$ & 0.50 \\
\hline RF-C & $2 \mathrm{UV} \%$ & $\begin{array}{c}\text { Beta blocker } \\
\text { Hypertension } \\
\text { Obesity }\end{array}$ & $\begin{array}{l}0.04 \\
0.02 \\
0.05\end{array}$ & 48.07 & $\begin{array}{r}-3.41 \\
3.20 \\
3.15 \\
\end{array}$ & 0.69 \\
\hline CAD-C & $0 \mathrm{~V} \%$ & $\begin{array}{c}\text { Dyslipidemia } \\
\text { Hypertension } \\
\text { Obesity }\end{array}$ & $\begin{array}{l}0.02 \\
0.03 \\
0.04\end{array}$ & 48.24 & $\begin{array}{r}20.41 \\
11.84 \\
0.85\end{array}$ & 0.64 \\
\hline
\end{tabular}

$\mathrm{r}^{2}=$ coefficient of determination; $0 \mathrm{~V} \%=$ percentage of pattern with no variation; $2 \mathrm{UV} \%=$ percentage of pattern with two unlike variations; hs-CRP = high-sensitivity C-reactive protein; $\mathrm{ACE}=$ angiotensin-converting enzyme; $\mathrm{RF}-\mathrm{T}=$ risk factor-trained; $\mathrm{CAD}-\mathrm{T}=$ coronary artery disease-trained; $\mathrm{RF}-\mathrm{C}=$ risk factor-control; CAD-C = coronary artery disease-control; PCI = percutaneous coronary intervention; ANCOVA and linear regression. Significance level of $\mathrm{p}<0.05$. 


\section{Correlation between heart rate variability indices and $\mathrm{C}$-reactive protein}

A significant and positive correlation was found between $0 \mathrm{~V} \%$ (sympathetic modulation) and hs-CRP before (CAD-T, $\mathrm{r}=0.78$; RF-T, $\mathrm{r}=0.85$, with $\mathrm{p}<0.001$ ) and after IT (CAD-T, r=0.80; RF-T, r=0.97, with $\mathrm{p}<0.001$ ). With regard to $2 \mathrm{UV} \%$ (parasympathetic modulation), a significantly relevant correlation was found with hs-CRP before (CAD-T, $\mathrm{r}=-0.74$; RF-T, $\mathrm{r}=-0.78$, with $\mathrm{p}<0.001)$ and after IT (CAD-T, $\mathrm{r}=-0.75$; $R F-T, r=-0.86$, with $p<0.001)$. Spectral indices did not correlate with hs-CRP $(p>0.05)$.

\section{Discussion}

This study demonstrated that IT based on VAT led to significant improvements in the autonomic modulation of HR as well as a reduction in hs-CRP levels. Furthermore, the present study showed that hs-CRP levels are positively associated with sympathetic modulation and negatively associated with parasympathetic modulation.

Notably, IT at the VAT level promoted an increase in parasympathetic modulation in both groups RF-T and CAD-T, while the reduction in sympathetic modulation was observed only for the RF-T group. Previous studies have shown that autonomic adaptions can be attributed to a reduction in efferent sympathetic neural outflow to the sinoatrial node ${ }^{22,23}$. Other mechanisms that result in an increase in vagal modulation through exercise training include the shear stress-induced up-regulation of endothelial nitric oxide (NO) synthase. Recent research has demonstrated that nitric oxide, which is widely recognized as an endothelial control mechanism, is also a vagal modulator. In addition, NO exerts a facilitative effect on the afferent baroreflex and augments central and peripheral vagal neuronal activity $^{24}$. Regarding methodological aspects of HRV analysis, although the symbolic analysis was more efficient in identifying changes in cardiac autonomic control than spectral analysis, this method combined with standard linear parameters can improve the performance of HRV analysis. Moreover, this finding was important for determining the applicability of symbolic analysis as a tool to evaluate autonomic adaptation-induced exercise training.

A significant decrease in CRP levels was observed in both trained groups. Particularly in the RF-T group, the decreases in the hs-CRP level indicated a reduced CAD risk after IT. The CAD-T group showed a greater reduction in the hs-CRP level than the RF-T group, which may suggest that high-risk individuals benefit more from IT than those with lower risk. In fact, this finding is consistent with previous observations showing that individuals with a high level of physical performance demonstrate lower hs-CRP levels than individuals with a sedentary lifestyle, regardless of gender and associated risk factors ${ }^{25}$.

Recent studies have shown that increased parasympathetic modulation may also play a role in mediating the inhibition of the inflammatory response observed in trained individuals ${ }^{26-28}$. The authors of these studies believe that one of the alternative mechanisms leading to reduced levels of circulating pro-inflammatory cytokines involves the cholinergic anti-inflammatory pathway ${ }^{4}$. In this pathway, acetylcholine inhibits the synthesis and release of pro-inflammatory cytokines by macrophages and other cytokine-producing cells by activating the alpha-7 nicotinic receptor (nAChR $\alpha 7$ ), which is expressed at the plasma membrane of these immune cells, resulting in reduced CRP levels ${ }^{4}$.

Singh et al. ${ }^{29}$ found a correlation between the linear indices of HRV, which reflect sympathetic modulation, and hs-CRP. These authors suggest that sympathetic activation promotes an increased concentration of circulating catecholamines, thereby stimulating the synthesis and release of pro-inflammatory cytokines. The adaptation of the sympathetic autonomic modulation of HR in the RF-T group, as shown by the reduced $0 \mathrm{~V} \%$ after IT, may also be considered an important pathway contributing to reduce CRP levels.

Analysis of the correlation between HRV indices and hs-CRP levels, adjusted according to clinical variables (angioplasty $>3$ months), the use of medications (beta-blockers, ACE inhibitor, and hypolipidemic agents), and cardiovascular risk factors (hypertension, dyslipidemia, and obesity), indicated that the decrease in hs-CRP levels after IT was negatively correlated with the $2 \mathrm{UV} \%$ (which reflects the parasympathetic modulation of HR) and positively correlated with the $0 \mathrm{~V} \%$ (which reflects the sympathetic modulation of HR). These findings reinforce the notion of a cholinergic anti-inflammatory pathway, and the anti-inflammatory properties of acetylcholine, and suggest that vagal modulation may inhibit the production of pro-inflammatory mediators, and thus establishing the causality link between both measures.

With regard to BP, both trained groups presented a decrease in systolic and diastolic BP at rest after IT. Several mechanisms may be involved in the reduction in BP, such as decreased sympathetic tone in smooth muscle cells in the arterial wall and possible increase in NO bioavailability that decreases peripheral vascular resistance ${ }^{24,30}$.

It is noteworthy that the $\mathrm{RF}$ and $\mathrm{CAD}$ groups are different in relation to presence of risk factors and 
medication use. The same can be observed between the trained and control RF groups. Considering that cardiovascular risk factors and medication may affect the HRV and the hs-CRP, analysis of covariance and linear regression showed that cardiovascular risk factors, such as dyslipidemia, hypertension, and obesity, led to a significant negative effect on $0 \mathrm{~V} \%$ (sympathetic modulation) and on $2 \mathrm{UV} \%$ (parasympathetic modulation) in the trained and control groups. Therefore, IT represents an important non-pharmacological therapeutic approach that should be included in the cardiac rehabilitation program of patients with CAD in view of its benefits in reducing risk factors and preventing the progression of CAD. On the other hand, medications such as beta-blockers and ACE inhibitors can attenuate vasoconstriction and sympathetic modulation, improving autonomic modulation of $\mathrm{HR}^{31}$. Hypolipidemic agents and ACE inhibitors have beneficial effects on hs-CRP because these drugs act on the control of lipid profile and hypertension, which are important risk factors to the development of atherosclerosis ${ }^{32}$.

The results of the present study may offer new possibilities in the field of cardiac rehabilitation, with respect to exercise training programs at VAT level. Cardiorespiratory parameters obtained at the VAT are of fundamental clinical importance to diagnosis, prescription of physical exercise, evaluation and re-evaluation of functional aerobic capacity, and monitoring of patients' development during exercise training programs. Furthermore, these results provide new insight into the main effects of IT on cardiac autonomic modulation and inflammation that could be expected in a larger sample. Thus, we can further develop the IT program based on VAT intensities as a new treatment protocol for cardiac patients.

\section{Study limitations}

The autonomic adaptations promoted by the IT program are restricted to male patients with CAD and/or cardiovascular RF, which prevents us from generalizing these results to women and other cardiac diseases. Other limitations were the small sample and the fact that the present study did not include a group of healthy male subjects. The latter is especially important considering that the symbolic indices and hs-CRP present high inter-individual variability. Moreover, other inflammatory markers such as interleukin 6, fibrinogen, soluble intercellular adhesion molecule-1, and serum amyloid A, as well as echocardiogram were not measured. Furthermore, the CPET in cardiac rehabilitation centers still remains inaccessible, mainly due to the complexity and high costs of this technology. However, considering its importance, strong efforts are needed to encourage the use of CPET in exercise intensity assessment and prescription of cardiac rehabilitation programs.

\section{Conclusion}

Interval training program based on VAT level led to improve in cardiac autonomic modulation, evidenced by increase in the parasympathetic modulation and decrease in the sympathetic modulation, associated with reduction of hs-CRP.

\section{Acknowledgements}

This research was supported by Conselho Nacional de Desenvolvimento Científico e Tecnológico (CNPq), Brazil [grant numbers 478601/2010-7, 308348/2009-5 and 131594/2011-7]. We wish to thank Alberto Porta, $\mathrm{PhD}$, for providing the program for symbolic analysis.

\section{References}

1. von Känel R, Carney RM, Zhao S, Whooley MA. Heart rate variability and biomarkers of systemic inflammation in patients with stable coronary heart disease: findings from the Heart and Soul Study. Clin Res Cardiol. 2011;100(3):241-7. http://dx.doi.org/10.1007/s00392-010-0236-5. PMid:20857123.

2. Taçoy G, Açikgöz K, Kocaman SA, Ozdemir M, Cengel A. Is there a relationship between obesity, heart rate variability and inflammatory parameters in heart failure? J Cardiovasc Med (Hagerstown). 2010;11(2):118-24. http://dx.doi.org/10.2459/ JCM.0b013e328332e730. PMid:19809354.

3. Haensel A, Mills PJ, Nelesen RA, Ziegler MG, Dimsdale JE. The relationship between heart rate variability and inflammatory markers in cardiovascular diseases. Psychoneuroendocrinology. 2008;33(10):1305-12. http:// dx.doi.org/10.1016/j.psyneuen.2008.08.007. PMid:18819754.

4. Tracey KJ. The inflammatory reflex. Nature. 2002;420(6917):8539. http://dx.doi.org/10.1038/nature01321. PMID: 12490958.

5. Nolan RP, Jong P, Barry-Bianchi SM, Tanaka TH, Floras JS. Effects of drug, biobehavioral and exercise therapies on heart rate variability in coronary artery disease: a systematic review. Eur J Cardiovasc Prev Rehabil. 2008;15(4):38696. http://dx.doi.org/10.1097/HJR.0b013e3283030a97. PMid:18677161.

6. Cornish AK, Broadbent S, Cheema BS. Interval training for patients with coronary artery disease: a systematic review. Eur J Appl Physiol. 2011;111(4):579-89. http:// dx.doi.org/10.1007/s00421-010-1682-5. PMid:20972578.

7. Currie KD, Rosen LM, Millar PJ, McKelvie RS, Macdonald MJ. Heart rate recovery and heart rate variability are unchanged in patients with coronary artery disease following 12 weeks of high-intensity interval and moderate-intensity endurance exercise training. Appl Physiol Nutr Metab. 
2013;38(6):644-50. http://dx.doi.org/10.1139/apnm-20120354. PMid:23724882.

8. Warburton DE, McKenzie DC, Haykowsky MJ, Taylor A, Shoemaker P, Ignaszewski AP, et al. Effectiveness of highintensity interval training for the rehabilitation of patients with coronary artery disease. Am J Cardiol. 2005;95(9):1080-4. http://dx.doi.org/10.1016/j.amjcard.2004.12.063. PMid:15842976.

9. Currie KD, Dubberley JB, McKelvie RS, MacDonald MJ. Low-volume, high-intensity interval training in patients with CAD. Med Sci Sports Exerc. 2013;45(8):1436-42. http:// dx.doi.org/10.1249/MSS.0b013e31828bbbd4. PMid:23470301.

10. Munk PS, Butt N, Larsen AI. High-intensity interval exercise training improves heart rate variability in patients following percutaneous coronary intervention for angina pectoris. Int J Cardiol. 2010;145(2):312-4. http://dx.doi.org/10.1016/j. ijcard.2009.11.015. PMid:19962772.

11. Gamelin FX, Berthoin S, Bosquet L. Validity of the polar S810 heart rate monitor to measure R-R intervals at rest. Med Sci Sports Exerc. 2006;38(5):887-93. http://dx.doi. org/10.1249/01.mss.0000218135.79476.9c. PMid:16672842.

12. Malliani A, Pagani M, Lombardi F, Cerutti S. Cardiovascular neural regulation explored in the frequency domain. Circulation. 1991;84(2):482-92. http://dx.doi.org/10.1161/01. CIR.84.2.482. PMid:1860193.

13. Porta A, Guzzetti S, Montano N, Furlan R, Pagani M, Malliani A, et al. Entropy, entropy rate, and pattern classification as tools to typify complexity in short heart period variability series. IEEE Trans Biomed Eng. 2001;48(11):1282-91. http:// dx.doi.org/10.1109/10.959324. PMid:11686627.

14. Wasserman K, Hansen JE, Sue D, Whipp BJ, Casaburi R. Principles of exercise testing and interpretation. 4th ed. Philadelphia: Williams and Wilkins; 1999.

15. Fletcher GF, Balady GJ, Amsterdam EA, Chaitman B, Eckel R, Fleg J, et al. Exercise standards for testing and training: a statement for healthcare professionals from the American Heart Association. Circulation. 2001;104(14):1694-740. http://dx.doi.org/10.1161/hc3901.095960. PMid:11581152.

16. Zamunér AR, Catai AM, Martins LE, Sakabe DI, Da Silva E. Identification and agreement of first turn point by mathematical analysis applied to heart rate, carbon dioxide output and electromyography. Braz J Phys Ther. 2013;17(6):614-22. http://dx.doi.org/10.1590/S1413-35552012005000129. PMID: 24346296.

17. Higa MN, Silva E, Neves VF, Catai AM, Gallo L Jr, Silva de Sá MF. Comparison of anaerobic threshold determined by visual and mathematical methods in healthy women. Braz J Med Biol Res. 2007;40(4):501-8. http://dx.doi.org/10.1590/ S0100-879X2007000400008. PMid:17401493.

18. Sirol FN, Sakabe DI, Catai AM, Milan LA, Martins LEB, Silva E. Comparação dos níveis de potencia e da frequência cardíaca no limiar de anaerobiose determinado por dois métodos indiretos. Rev Bras Fisioter. 2005;9(2):7.

19. Pithon KR, Martins LEB, Gallo L Jr, Catai AM, Silva E. Comparação das respostas cardiorrespiratórias entre exercício de carga constante e incremental abaixo, acima e no limiar de anaerobiose ventilatório. Rev Bras Fisioter. 2006;10(2):1639. http://dx.doi.org/10.1590/S1413-35552006000200005.

20. Lara Fernandes J, Serrano CV Jr, Toledo F, Hunziker MF, Zamperini A, Teo FH, et al. Acute and chronic effects of exercise on inflammatory markers and B-type natriuretic peptide in patients with coronary artery disease. Clin
Res Cardiol. 2011;100(1):77-84. http://dx.doi.org/10.1007/ s00392-010-0215-x. PMid:20835904.

21. Cohen J. Statistical power analysis for the behavioral sciences. $2^{\text {nd }}$ ed. Ilinois: Routledge; 1988.

22. Blomqvist CG, Saltin B. Cardiovascular adaptations to physical training. Annu Rev Physiol. 1983;45(1):169-89. http://dx.doi.org/10.1146/annurev.ph.45.030183.001125. PMid:6221687.

23. Dixon EM, Kamath MV, McCartney N, Fallen EL. Neural regulation of heart rate variability in endurance athletes and sedentary controls. Cardiovasc Res. 1992;26(7):713-9. http://dx.doi.org/10.1093/cvr/26.7.713. PMid:1423437.

24. Buch AN, Coote JH, Townend JN. Mortality, cardiac vagal control and physical training--what's the link? Exp Physiol. 2002;87(4):423-35. http://dx.doi.org/10.1111/j.1469-445X.2002. tb00055.x. PMid:12392106.

25. Goldhammer E, Tanchilevitch A, Maor I, Beniamini Y, Rosenschein U, Sagiv M. Exercise training modulates cytokines activity in coronary heart disease patients. Int J Cardiol. 2005;100(1):93-9. http://dx.doi.org/10.1016/j. ijcard.2004.08.073. PMid:15820291.

26. Soares-Miranda L, Negrao CE, Antunes-Correa LM, Nobre TS, Silva P, Santos R, et al. High levels of C-reactive protein are associated with reduced vagal modulation and low physical activity in young adults. Scand J Med Sci Sports. 2012;22(2):278-84. http://dx.doi.org/10.1111/j.16000838.2010.01163.x. PMid:20626701.

27. Hamer M, Steptoe A. Association between physical fitness, parasympathetic control, and proinflammatory responses to mental stress. Psychosom Med. 2007;69(7):660-6. PMID: 17724255.

28. Heffernan KS, Jae SY, Vieira VJ, Iwamoto GA, Wilund $\mathrm{KR}$, Woods JA, et al. C-reactive protein and cardiac vagal activity following resistance exercise training in young African-American and white men. Am J Physiol Regul Integr Comp Physiol. 2009;296(4):R1098-105. http://dx.doi. org/10.1152/ajpregu.90936.2008. PMid:19193941.

29. Singh P, Hawkley LC, McDade TW, Cacioppo JT, Masi $\mathrm{CM}$. Autonomic tone and $\mathrm{C}$-reactive protein: a prospective population-based study. Clin Auton Res. 2009;19(6):367-74. http://dx.doi.org/10.1007/s10286-009-0019-0. PMid:19504232.

30. Luk TH, Dai YL, Siu CW, Yiu KH, Chan HT, Lee SW, et al. Effect of exercise training on vascular endothelial function in patients with stable coronary artery disease: a randomized controlled trial. Eur J Prev Cardiol. 2012;19(4):830-9. http:// dx.doi.org/10.1177/1741826711415679. PMid:21724681.

31. Bilchick KC, Berger RD. Heart rate variability. J Cardiovasc Electrophysiol. 2006;17(6):691-4. http://dx.doi.org/10.1111/ j.1540-8167.2006.00501.x. PMid:16836727.

32. Prasad K. C-reactive protein (CRP)-lowering agents Cardiovasc Drug Rev. 2006;24(1):33-50. http://dx.doi. org/10.1111/j.1527-3466.2006.00033.x. PMid:16939632.

\section{Correspondence \\ Ester da Silva}

Universidade Federal de São Carlos - UFSCar

Departamento de Fisioterapia

Núcleo de Pesquisa em Exercício Físico

Rodovia Washington Luiz, Km 235

CEP 13565-905, São Carlos, SP, Brazil

e-mail: nayaratamburus@hotmail.com, esters@ufscar.br 